\title{
Culturally appropriate pedagogy: the case of group learning in a Confucian Heritage Culture context
}

\author{
Phuong-Mai Nguyen ${ }^{\mathrm{a} *}$, Cees Terlouw ${ }^{\mathrm{b}}$ and Albert Pilot $^{\mathrm{a}}$ \\ ${ }^{\mathrm{a}}$ Utrecht University; ${ }^{\mathrm{b}}$ Twente University, The Netherlands
}

\begin{abstract}
Cultural heritage preservation has become a much-debated topic in recent decades. This paper contributes to the call for educational approaches that take a society's cultural diversity into account. It also attempts to draw attention to non-Western societies, where educational theories and practices from elsewhere (the West) have been imported and applied without proper consideration for the host culture's heritage. To illustrate the intricacy of developing such a culturally appropriate pedagogy, a case study of using group learning strategies in a Confucian Heritage Cultural context is introduced, which closely examines both educational and cultural issues. The results of this examination reveal a complex web of cultural conflicts and mismatches that are likely to happen when a Western educational methodology is applied in another context without rigorous adaptation to improve compatibility with the host culture.
\end{abstract}

\section{The WHY in culturally appropriate pedagogy}

Key challenges for educators

The two factors that have recently generated concern regarding culturally appropriate pedagogy are globalization and multiculturalism. Beginning in the 1990s, the process of globalization very quickly occupied centre stage for political, economic and cultural debates, with critical consequences for both educational policy and practice. Owing to globalization pressures, various educators have become concerned about making education more sensitive to global developments, helping to prepare new generations for a new international reality by providing them with the knowledge, skills and attitudes that will enable them to cope with rapid societal changes. In addition, student populations have become increasingly and undeniably

\footnotetext{
*Corresponding author: Bevinlaan 205, 3527 ED, Utrecht. Email: m.p.nguyen@ivlos.uu.nl
} 


\section{Phuong-Mai, Nguyen et al.}

diverse around the globe. Multiculturalism has shifted from a trendy buzzword to a wave of indelible influence on education.

Thomas (1997) identified two key challenges for educators: (1) to decide what the key elements are in the process of globalization that are likely to affect education and schooling, and to assess which of these elements can be used as part of the core strategy for curriculum planning in schools and teacher training; (2) to decide and deal with the social mores - the fabric of a cultural niche, with teaching and learning that should be more culturally sensitive.

The second challenge relates to the issue of culturally appropriate pedagogy, a pedagogy that focuses on educational competence in a global context, and which addresses the cultural context of learners and teachers. Other terms used to address this type of pedagogy include: culturally responsive, culturally respective, culture-sensitive, culturallyrooted and culturally relevant. Though the terms may differ, the common spirit is the same: respect for cultural differences.

\section{The WHAT of culturally appropriate pedagogy}

The call for culturally appropriate pedagogies began in the 1990s, and found supportive echoes in all educational research fields. The need for a new pedagogy, which takes into account cultural factors and responses arises from two educational environments: first, environments with high levels of cultural diversity: the US, Australia, and Canada are three obvious examples of historic immigrant nations. In a more recent development, multiple European countries have also experienced an influx of immigrants. For example, more than $10 \%$ of the Dutch population is presently of foreign descent, mostly due to labour migration (Compact Geography of the Netherlands, 2001). Teachers from these countries face the challenge of educating children who come from a multiplicity of cultural backgrounds.

Another important development relates to the importation of Western educational theories and practices in other parts of the world. This is a critical issue for nonWestern and, especially, developing countries. With modern technological advances, less-developed nations have been able to apply the newest approaches quickly and catch up with the most recent innovations that were initiated thousands of kilometres away, thereby taking a huge developmental leap without implementing a research or testing phase. The issue is to what extent culture can render Western approaches ineffective and perhaps even counterproductive. The present paper focuses on this particular issue. It represents an attempt to shed more light on the complicated nature of culturally appropriate pedagogy, especially in non-Western environments. In contrast to the rich amount of research on culturally appropriate pedagogy in Western nations, our area of focus suffers from serious academic neglect.

\section{The fight and the right to be different}

Many researchers see globalization as a transcendental process which disregards national boundaries and regional variations. It has been perceived as the 'death 
knell' of the nation-state and, therefore, a major factor in the erosion of national and cultural identities (Water, 1995). In many non-Western (developing) nations, together with the wave of importing modern technologies, the current trend of importing educational policies, theories and practices from the West has resulted in the neglect of one's cultural heritage. This has been the consequence of a drive to modernize educational systems. By doing this, governments hope that more upto-date teaching and learning methods will give them a competitive edge and eventually lead to greater economic success and more political control (Thomas, 1997). The enthusiastic application of 'constructivism', 'student-centred learning', 'active learning' and 'autonomous learning', to name a few, in Africa and Asia illustrates this trend. In Korea, for instance, $100 \%$ of kindergarten teachers recently advocated the US/Western child-centred educational philosophy as the main aim of preschool education (Young-Ihm, 2002). Since 2000, it has been mandated in all Hong Kong schools that teacher appraisal must be implemented using an appraisal model firmly grounded in fairly traditional Western approaches and understanding (Walker \& Dimmock, 2000). The all-reaching Hong Kong education reforms in 1997 were driven very much by global educational trends and were reflective of School-Based Management policies emanating from Western nations (Dowson et al., 2000). In China, more and more schools are being established with innovative modern teaching and learning methodologies imported from the other side of the world. An experimental school system was recently developed in Vietnam, where children are now educated in a Western way, with a focus on learning autonomy etc.

However, initial research shows that such programmes produce mixed results. Young-Ihm's study (2002) points to a large discrepancy between what teachers believe (US/Western models of child-centred approaches) and what they actually practice (remaining traditional). Walker \& Dimmock (2000) have claimed that this 'cross-cultural cloning' should be questioned and that a search for more culturally relevant methods needs to take place. Also in Hong Kong, the emphasis on a Western type of university culture (public accountability, staff appraisal, promotion and substantiation based increasingly on an individual's ability to conform to the shift in work culture etc.) has resulted in the loss of experienced staff (Dowson et al., 2000). Similarly, in China, The Economist ('Roll over Confucius', 25 January 2003) reported that innovative schools with modern US- and Western-based learning are being shunned by parents in favour of schools that retain traditional educational methods (Munro-Smith, 2003). In Vietnam, the number of parents that have registered their children in experimental schools has rapidly increased since these schools were forced to abandon 'progressive methods of teaching' and returned to the national education programme.

The importation or cloning of policies, theories and practices, as mentioned above, might not be a new phenomenon. Though latently present for some time, the trend has become more pronounced in recent years as a direct result of the urge to catch up with modern (Western) standards in education. Policy makers and practitioners, under pressure to reform, too often concentrate on identifying 'surface 
similarities' and assume that what has been done successfully over there would produce similar outcomes here (Walker \& Dimmock, 2000). Witty et al. (1998) point out that adopting policies, theories and practices across cultures without recognizing their distinctive historical and cultural dimensions risks 'false universalism'. One size cannot fit all. Each culture has the right and each should fight to express this, and develop what is best for its own particular situation.

\section{The case of group learning in a Confucian Heritage Cultural context: An introduction}

This case study is meant to be seen as a vehicle that sheds light on the complexity of culturally appropriate pedagogy. It illustrates how a seemingly culturally neutral intervention can fail in other context.

The Confucian Heritage Culture (CHC) is dominant in China and other countries strongly influenced by China in the region's long history (Vietnam, Japan, Korea, Singapore, Taiwan, Hong Kong and Malaysia). Much research has demonstrated that CHC learners are able to excel when working in group settings. This has been attributed to a collectivist orientation, plus additional Confucianism values that emphasize interpersonal relationships and in-group cohesion. Learners from CHC contexts prefer working in groups and perform better in groups (Chan and Watkins, 1994; Biggs, 1990; Earley, 1989; Hofstede \& Hofstede, 2005; Park, 2002; Sullivan, 1996; Tang, 1996). Consequently, cooperative learning strategies have been strongly recommended for collectivist learners (Salili, 1996). Group learning is assumed to be culturally appropriate in CHC and many Asian collectivist nations.

Phuong-Mai et al. (2005a) attempted to explore whether the fixed assumption that group learning is culturally appropriate in CHC nations holds true under the microscope of academic research. This study revealed a series of cultural conflicts and mismatches with respect to: (a) the general characteristics/consequences of Western models of group learning and; (b) norms, values and practices associated with $\mathrm{CHC}$. The authors concluded that, although group learning may be appropriate in CHC nations, Western models of group learning may NOT be appropriate.

The search for clarification of the issue identified above, led us to Hosfstede's work. According to Hofstede \& Hofstede (2005), culture differs along five dimensions: power distance, individualism-collectivism, masculinity-femininity, uncertainty avoidance, and short-long versus term-time orientation. We shall use these five dimensions to clarify the problems with using Western-based educational approaches in CHC nations. The definitions and statistics referred to in the following are taken from the second edition of Cultures and Organization (Hofstede \& Hofstede, 2005).

\section{The first dimension: power distance}

Power distance is the extent to which less powerful members of institutions expect and accept that power is distributed unequally. CHC nations score high on the 
Power Distance Index. Malaysia scores highest with 104; China: 80; Singapore: 74; Vietnam: 70; Hong Kong: 68, Korea: 60; Taiwan: 58; and Japan: 54.

Societal stability, according to Confucius, is based on unequal relationships between people-in the educational realm this is the teacher-student dyad. Teachers in CHC nations are not only teachers but also models of correct behaviour. Students stand up when the teacher enters the classroom, and are allowed to speak only when invited to do so. Rarely does a student dare to question a teacher. The teacher is treated with deference, even when the student is no longer at school, and this respect remains for life (Kennedy, 2002; Scollon \& Scollon, 1995). There is a saying in Korea: 'One does not dare to step on a teacher's shadow'. In Vietnam and China, a teacher is ranked just below the King and above the father: the King-the Teacherthe Father. According to Vietnamese Education law, the first criterion for a teacher is to be of 'good moral quality, ethically and ideologically' (Education Law, 1998). Every year, 20 November is officially dedicated to honour teachers. It is a day to express gratefulness-especially for alumni to visit their past teachers.

Group learning, from a Western perspective, means working within a social constructivist environment in which students, using their collective knowledge, may exceed the knowledge of their teacher and thereby bring the teacher's knowledge into question. The change of status also means that a quiet, orderly class will no longer exist and various social complex situations will materialise. Let us examine what occurred in a Vietnamese school when criticism occurred. While giving his lesson, a teacher somehow made a mistake and gave the wrong translation of the word 'redneck'. A student spotted the mistake. Instead of accepting that this was a mistake, the teacher felt offended and said: 'If you think you know more than me, come $u p$ here and replace me as the teacher!' (Personal communication, 2002).

\begin{abstract}
Question 1: Is it possible for a teacher to lower him/herself from a position of sacred and inviolable correctness to someone who dares to accept that (s)he might make mistakes or that (s)he does not know the answer? When encountering such problems in the teacher-student relationship, is it possible for a teacher to forget that (s)he is always right; to forget that (s)he is a ruler so that problems can be resolved in a spirit of cooperation and social constructivism?
\end{abstract}

Owing to the strong need for dependence, Hofstede \& Hofstede (2005, p. 51) argued that when the educational process is teacher-centred the teacher outlines the intellectual paths to be followed and initiates all communication (Chan, 1999; Samuelowicz, 1987). Respondents in a study conducted by Phuong-Mai et al. (2005b) agreed that teachers should always have the right answer to all questions coming from students. The teacher is considered to be a guru who is supposed to satisfy learners in the search for the truth (in knowledge) and virtues (in life). In addition to textbooks, teachers represent the ultimate, the one and the only source of knowledge in the classroom (Maley, 1983). The stream of knowledge passes along a one-way-street from teacher to students. The reverse occurs in Western group learning situations. Knowledge begins with the students themselves and, within the group, the students maintain an even higher level of knowledge. The teacher, 
according to Johnson \& Johnson (1994), plays the role of a guide, a facilitator who moves from group to group to observe and motivate learning.

Question 2: Is it possible for a teacher to lower him/herself from a position of honour, being the ultimate source of knowledge, to a relatively silent and patient facilitator?

Finally, power distance does have an influence on the student-student relationship. According to Johnson \& Johnson (1994), shared leadership means that each member has a job to do, and the team has no formal leader. In contrast, Confucius stated that society is based on unequal relationships. The father is the leader in the CHC family; the teacher is the leader in CHC class. There is also a class prefect, several unit leaders and sub-leaders for small groups. There are strong hierarchy rules. If there is a group, there is a leader. Without a leader, the group is not stable in this view (Phuong-Mai et al., 2005b).

Question 3: In what way could CHC learners surmount the need for a formal leader in group learning and embrace an equally shared leadership position according to the Western model of group learning?

\section{Second dimension: individualism-collectivism}

Individualistic societies are defined as those where ties between individuals are loose. Individuals are expected to look after themselves and their immediate family. Collectivist societies are those where people are integrated into strong, cohesive ingroups from birth onwards. These in-groups continue to protect them throughout their lifetime in exchange for unquestioning loyalty. CHC nations score low on the Individualism Index (IDV): Japan (46); Hong Kong (25); Singapore, China and Vietnam (20); Korea (18); and Taiwan (17).

A study focusing on the work ethic among five groups of managers in North Vietnam, South Vietnam, South China (cosmopolitan), Southwest China and the US showed that North Vietnam is more individualistic than South Vietnam and Southeast China, but, contradictorily, (at the same time) the most collectivist of all (Ralston et al., 1999). Clearly, collectivism is not simply the mirror opposite of individualism! These two concepts need to be considered as two separate continua. This point of view is supported by Triandis (1995).

In their study of CHC learners at the University of South Australia, Kee andWong (2003) found that there is a preference to work individually among CHC learners so that they can have full control of the final product. Park's study (2002) showed that Korean students have negative preferences for group learning, that this preference reflects the individualistic and competitive spirit found in Korean classrooms. Similarly, Agelasto argued that, in terms of pedagogy, competition in China is generally more highly valued than cooperation (Agelasto, 1998). In her study of secondary schooling during the Cultural Revolution, Susan Shrik (1982, cited in Agelasto, 1998) stated that 'cooperative learning rarely exists at any level of education in China. Study was organized individually, with no collective goal. Furthermore, the structure of educational selection and job assignment placed classmates in direct, 
face-to-face competition with each other'. Note also that her book was entitled Competitive Comrades.

Question 4: If collectivism and individualism are not opposites and each of them represents a complex construct, can collectivism actually act as a culturally supportive background for group-working success? How can one explain the contradictory results of the $\mathrm{CHC}$ learners who prefer to work individually?

Losing face inflicts extremely serious personal damage, and one should try to avoid it at any price (Hofstede \& Hofstede, 2005). Being frightened of losing face, many $\mathrm{CHC}$ learners dare not volunteer personal ideas, either for fear of being considered silly or for fear of making others feel humiliated (Cocroft \& Ting-Toomey, 1994; Ting-Toomey, 1988; Tsui, 1996). Allowing a person to save face is more important than telling the truth. In this way, both parties, for the sake of 'giving face', 'saving face' and 'asserting face', keep their mouths shut. Researchers (Jehn \& Weldon, 1992; Kirkbride et al., 1991; Tse et al., 1994) have shown that CHC learners that are more concerned about these issues tend to use more indirect styles such as avoidance (not discussing the topic of conflict) and assuming an obliging style (greater concern for the other's interest in the conflict than one's own).

In a collectivist classroom, the virtue of harmony reigns supreme. Confrontations and conflicts are to be avoided (Hofstede \& Hofstede, 2005; Leung, 1997; TingToomey, 1988). Teachers dream of a class with little noise, and students try hard to make this dream come true. In a group setting, Chinese learners suppress their personal desires, avoid conflicts and hence avoid criticizing their peers or claiming any authority (Carson \& Nelson, 1996; cited in Jones, 1999). CHC learners' main goal is to maintain group harmony, and this affects the nature of group interaction. Data in the questionnaires conducted by Phuong-Mai et al. (2005b) with Vietnamese respondents suggested that the more respondents appreciate the one-for-all mentality, the more they were willing to sacrifice for the sake of group harmony, the less they wanted differences of opinion to be voiced and the less they were willing to explore fallacies in the thinking of others. Many Vietnamese proverbs express this moral lesson: 'One time self-denial means nine times goodness'; 'Think seven times before speaking out'; 'Words cost no money, use them well to please others' etc. The Western approach of working in groups and dealing with conflict may therefore seem to be culturally inappropriate when the second premise of Johnson \& Johnson's cooperative learning (1994), entitled 'Face-to-Face Promotive Interaction', is applied in a CHC class. Challenging each other's conclusions and reasoning, advocating the exertion of effort, influencing each other's efforts, striving for mutual benefit, and maintaining a moderate level of arousal need to be seen in a different light. In their study, Neuman and Bekerman (2000) advised caution in introducing Asian students to a constructivist and cooperative learning approach.

Question 5: How strong an influence does the fear of losing face have on the effectiveness of group learning? How strong is the influence of attempting to maintain harmony on the effectiveness of group learning? 


\section{Third dimension: masculinity-femininity}

Masculinity is defined as standing for a society in which social gender roles are clearly distinct: men are supposed to be assertive, tough and focused on material success; women are supposed to be more modest, tender and concerned with the quality of life. Femininity symbolizes a society in which both men and women are supposed to be modest, tender, and concerned with the quality of life. CHC nation scores scatter on both sides of this continuum: Japan (95), China (66), Hong Kong (57), Singapore (48), Taiwan (45), Vietnam (40) and Korea (39).

The wide range of scores in $\mathrm{CHC}$ nations can be explained by the distinct characteristics of Confucianism, which interacts with this dimension. As such, CHC nations do not necessarily belong to either of the two sides. Examining Hofstede \& Hofstede's summary (2005, p. 142), we find CHC values on both sides of the masculinity and femininity dimensions. With respect to education and group learning, this dimension clearly affects the social status of males and females. Confucius preached that societal stability is based on five unequal relationships among people. One of these is the husband-wife dyad. The wife is subject to the husband. A proper woman in CHC nations is somebody who can live up to what are called the 'three follows' (at home she follows her father; when married, she follows her husband; when widowed, she follows her son). Many Asian brides still follow their husband by living in his family's house and by considering herself to be no longer a part of her own family, but a part of her husband's family. The old saying 'Having one son means having but having ten girls means having nothing', comes to mind. Tran Thi Van Anh $(2002)^{1}$ has shown that in Vietnamese textbooks girls and women are depicted as having traditional jobs in the home, working in the fields, and becoming nurses and doctors to take care of others (see Figure 1). Boys and men, on the other hand, play and work in social environments, become leaders, scientists or educated workers. Girls and women exhibit characteristics of sensitivity, diligence, shyness, often look for others' help and hold a lower position than males, while boys and men are strong, rational, self-confident, respectful and keen on technology (Vietnamese grade 1-5; Ethics grade 7; Citizenship education grade 9).
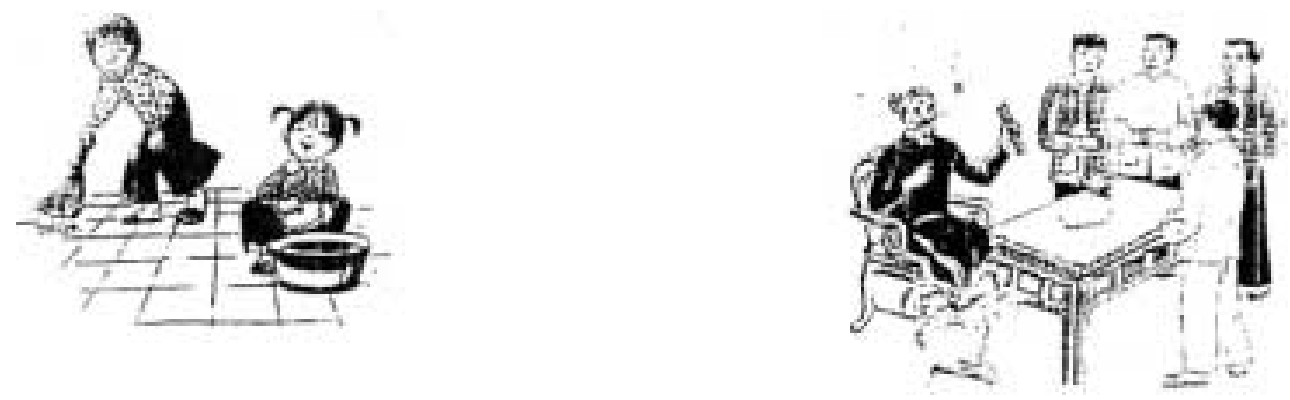

Figure 1. Illustration from Vietnamese textbooks (Tran Thi Van Anh, 2002): girls do housework; boys do important things (the father is teaching his sons about the power of sibling cooperation) 
Unfortunately, researchers have not yet reached a consensus concerning crossgender issues in group learning. Whether mixed gender groups can enhance learning and provide valuable opportunities to overcome gender discrimination remains a controversial issue. Sadker et al. (1991) showed that group learning may be less equitable for female learners than autonomous learning. Group learning may reinforce stereotypes and biases, and male learners may discredit females. Females talk less in mixed groups and are interrupted more often (Belenky et al., 1997). Sadker et al. (1991) stated that the differences and contradictory findings in cross-gender performance during cooperative learning suggest that, by itself, the implementation of group learning does not necessarily lead to a more equitable and effective learning environment.

Coming back to $\mathrm{CHC}$ nations and the traditionally passive role of women: if Western female learners are unlikely to achieve an equitable and equal role when participating in a group with mixed gender representation, how would such groups influence CHC female learners? Gajdusek and Gillotte (1995) also raise this question in their study aimed at female learners from cultures where women's voices or rights to a voice are challenged. Phuong-Mai et al. (2005b) showed that in Vietnam adult learners tend to admit that males have more influence in group discussions than females do and also have a greater chance to be elected group leader.

Question 6: In what way can female learners from CHC nations surmount their passive status in order to equally and actively participate in group learning?

\section{Fourth dimension: uncertainty avoidance}

Uncertainty avoidance is defined as the extent to which the members of a culture feel threatened by uncertainty or unknown situations. On this continuum, CHC nations again differ greatly: Japan (92), Korea (85), Taiwan (69), China and Vietnam (30), Hong Kong (29) and Singapore (8). Similar to the last dimension, distinct characteristics of Confucianism, which interact with this dimension, have created a set of values that represent both extremes. In general, CHC persons seem to have weak uncertainty avoidance with respect to notions of time and interpersonal relationship expressions, and strong uncertainty avoidance when it comes to moral social rules and education. With respect to group learning, the manner in which $\mathrm{CHC}$ people prefer structured tasks leads us to consider $\mathrm{CHC}$ learning styles.

For several thousand years, traditional exams in CHC contexts involved competitions where students had to memorize an enormous amount of literature. Today, CHC's rote learners are seen as students who are only capable of surface learning and re-production (Ballard \& Clanchy, 1984; Bradley \& Bradley, 1984; Samuelowicz, 1987; Chalmers and Volet, 1997). In addition to rote learning, CHC learners are described as quiet, shy, reticent and lacking initiative. They dislike public touching and overt displays of opinions or emotions (Harshbarger et al., 1986). CHC learners will not talk in class, expect the teacher to teach them everything they are expected to know, have little desire to discover for themselves, wish to be spoon-fed and, in turn, they are spoon-fed. The picture of passive, non-participative CHC learners and 
teacher-dominated classrooms is common (Scollon \& Scollon, 1994; Flowerdew \& Miller, 1995; Pierson, 1996).

Question 7: In what way can CHC learners become independent and autonomous enough to carry on group learning activities according to the expectations of Western models?

CHC learners have a strong preference for the visual (Lam Phoon, 1986; Suh \& Price, 1993; Yong \& Ewing, 1992). They like to read and obtain a great deal of visual stimulation. Lectures, conversations and oral directions without visual backup can be quite confusing and anxiety-producing, hence raising the level of uncertainty. This strong perceptual visual channel may be the result of CHC's idiographic writing system, which has pronounced visual properties. ${ }^{2}$ Learners with high uncertainty avoidance tend to be people who feel comfortable only with structured learning, precise objectives, detailed assignments and good instruction. They do not like predicting and guessing. In other words, they want to be told what they need to know and precisely how to prove that they have learnt it (Hofstede \& Hofstede, 2005; Munro-Smith, 2003). Kennedy (2002) argued that Chinese learners are more reflective than impulsive, that is they prefer an accurate, systematic approach. They feel the need for rapid and constant correction and have a low level of tolerance for ambiguity and uncertainty. Oxford \& Burry-Stock (1995) state that CHC learners are often detail- and precision-oriented, showing some features of the analytic and field-independent learning style. Open-ended discussions or vague group tasks may cause fuzziness and confusion. Respondents in the study conducted by Phuong-Mai et al. (2005b) expressed a high level of agreement that there must be detailed introductions and step-by-step guidelines from teachers in group learning and the reason why group learning is difficult is the lack of the task's guiding material. According to Strijbos (2000), the learning preferences mentioned above can be found in group work that has a high amount of structure, a well-structured task and algorithmic skills. This is the approach of the 'cooperative extreme'. The other approach, the 'collaborative learning extreme', requires a low amount of structure, an ill-structured task and a synthesis skill (Figure 2).

Apparently, group learning cannot always be organized with well-structured tasks, precise objectives and with all the details available. Discussion and open-ended group tasks (collaborative approach) play a very important role in the learning process and often give credit to learners who are more open to new ideas, are free thinking and are willing to take risks.

Question 8: In what way can CHC learners surmount the preference for a structured style in order to reach the level of collaborative participation in group work?

\section{The fifth dimension: short-term time orientation versus long-term time orientation}

A short-term time orientation is defined as valuing the past and present, especially respect for traditions, preservation of 'face' and fulfilling social obligations. A longterm time orientation values an orientation towards future rewards, in particular 


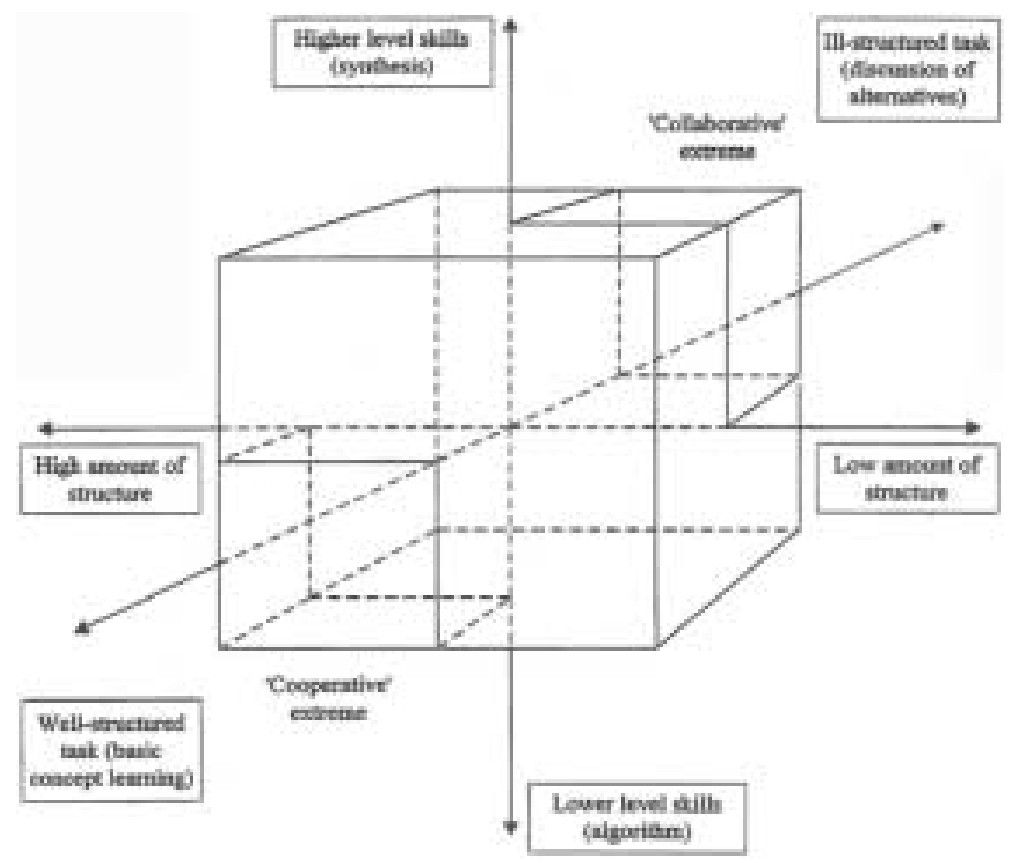

Figure 2. The dimensions of group learning

perseverance and thrift. The top six positions on the long-term orientation index (LTO) are occupied by six CHC nations: China (118), Hong Kong (96), Taiwan (87), Japan and Vietnam (80), and Korea (75).

Short-term time orientation cultures (STO culture) are associated with monochromic-time (M-time), whereas CHCs (long-term) are associated with polychromic-time (P-time). In $\mathrm{M}$-time cultures, time is divided into linear segments. $\mathrm{M}$-time cultures tend to emphasize clock time, schedules, appointments, promptness and measure units of time. Individuals in $\mathrm{M}$-time tend to focus on doing one thing at a

Table 1. Short-term versus long-term orientation (after Chang, 2003)

Short-term time orientation (more compatible with the West)

What are the deadlines for my assignments?

I have to contribute at every possible tutorial

I have to be in class by $3.15 \mathrm{pm}$ but I want to be out of there by $3.55 \mathrm{pm}$ so I can be at the next lecture on time
Long-term time orientation (more compatible with CHC nations)

The exam is around November, right? And there will be assignments sometime during the semester? OK!

So, OK, sometimes I contribute more, sometimes less. It evens up eventually anyway. No fuss! It's OK! I'll make it! As long as in the long run, I attend the tutorials and lectures, that's fine! 
time (Hall \& Hall, 1987). M-time is tangible and can be 'saved, spent, wasted, lost, made up ... and run out' (Hall, 1983). Personal interaction can be sacrificed to scheduling and efficiency demands.

In comparison, people in P-time tend to give relationships priority over 'artificial' clock time. Often, they intermix socio-emotional activities with instrumental, taskbased activities (Hall \& Hall, 1987). For CHC P-time people, time is the servant and tool of people, and it is adjusted to suit the needs of people. Time is limitless and not quantifiable. There is always more time. Wessel (2003) states that P-time people change plans and deadlines frequently, view schedules as goals instead of imperatives. High flexibility and lack of formal planning have been shown to be the management style in CHC nations (Chen, 1995). When having to cope with an inflexible deadline, Vietnamese people admit that this P-time mentality somewhat jeopardizes cooperation (Phuong-Mai et al., 2005b). A slang concept, but often used and very popular in Vietnam and Malyasia, is that of 'rubber time'. It indicates the extreme stretchable notion of time. The proverb 'wait till the water comes then hurriedly jump' is agreed to be a common phenomenon in group learning and could therefore jeopardize the group's effectiveness. Chang (2003) has illustrated these two types of orientations (see Table 1):

Question 9: In what way can CHC learners surmount the fluid time habit in order to manage and cope with time pressure in group learning, according to the Western model?

Though not directly related to culture, very large class sizes in CHC nations can be seen as a factor affecting group learning. In China, classes contain 50-60 students, while the legal maximum class size in Japan is 45 and 43 in Korea (Kirkpatrick, 1998). If an effective learning group should consist of no more than four students (Johnson \& Johnson, 1994), there would be 13-14 groups working simultaneously in a room of $9 \times 9$ metres. According to the Western standard of an optimal class-size of 1:15 (Achilles, 1996), a CHC class will not be ideal by any means for conducting effective group learning.

Question 10: In what way can the obstacles of class-size be surmounted in order to achieve effective group learning, according to the Western model?

These results, taken together, indicate that Western-style group learning is not totally culturally appropriate in CHC environments. Recent research (Messier, 2003) has shown that, in fact, traditional CHC lecture-based education generates higher achievement levels in CHC nations than Western cooperative learning strategies. Thus, it becomes critical to conduct research on how truly culturally appropriate methodologies can be implemented in CHC nations, instead of relying on imports that ignore the complexities of cultural learning environments.

\section{The HOW of culturally appropriate pedagogy?}

Many studies provide certain tips or ' 10 ways to' or refer to principles/strategies to answer the issue of how to develop culturally appropriate pedagogies. For example, Jackson (1994) identifies the following strategies for teachers to be used across 
grades and disciplines, assuming that they are recursive and interrelated: (1) build trust; (2) become culturally literate; (3) build a repertoire of instructional strategies; (4) use effective questioning techniques; (5) provide effective feedback; (6) analyse instructional materials; and (7) establish positive home-school relations. In another research handbook on culturally relevant and culturally responsive education, a list of strategies is presented, categorized into five groups: (1) classroom environment; (2) prior knowledge and cultural knowledge; (3) instruction based upon 'all children can learn' (4) language; (5) involvement with parents (Stevens et al., 2003).

However, there is a limited amount of research that tries to tackle the problem of culturally appropriate pedagogy in such a way that a valid model is presented with sufficient support from theories and plausible rationales. Two that deserve mentioning are summarized below.

\section{A simplified application of Hofstede's five dimensions}

In Table 2, Munro-Smith (2003) applies Hofstede's findings to put forward a simple model of culturally appropriate pedagogy. This is an attempt to design a course in which the teaching/learning mode is expected to be culturally suitable for a variety of international students at RMIT (Australia).

According to this model, for example, version (A) should suit most learners from a $\mathrm{CHC}$, version (B) for most students from India, version (C) for most Germans and version (D) for most Australians. This way of seeing culturally appropriate pedagogy obviously risks cultural stereotyping if applied superficially. The author of this model is highly aware of this and therefore also stated that 'Flexibility is the key'.

\section{Thomas's model of culturally appropriate pedagogy ${ }^{3}$}

Claiming that insufficient research exists in the area of cross-cultural pedagogy and that little attention has been given to translating existing information and research findings on learning cultures into teaching strategies and styles, Thomas (1997) emphasized the need to identify different cultural pedagogies and describe the impact they may have on improving educational quality. Based on his particular view of pedagogy, which consists of four essential components, he proposed a model of culturally appropriate pedagogy which is expected to be meaningful. It bridges

Table 2. A simplified application of culturally appropriate pedagogy

\begin{tabular}{|c|c|}
\hline Structured & Self-directed \\
\hline $\begin{array}{l}\text { A-collective, high power distance, high } \\
\text { uncertainty avoidance }\end{array}$ & $\begin{array}{l}\text { B-collective, low power distance, low } \\
\text { uncertainty avoidance }\end{array}$ \\
\hline $\begin{array}{l}\mathrm{C} \text {-individualistic, high power distance, high } \\
\text { uncertainty avoidance }\end{array}$ & $\begin{array}{l}\mathrm{D} \text {-individualist, low power distance, low } \\
\text { uncertainty avoidance }\end{array}$ \\
\hline
\end{tabular}


new values with the old, and places former knowledge and skills in the context of the new. We shall have a closer look at this model (Figure 3).

The first component in Figure 3, epistemological, refers to the knowledge base which all teachers need. The second component, process component, includes general activities engaged in. The third one, contextual component, refers to the sociocultural matrix in which language, religion and cultural tradition give a unique profile to the practice and development of pedagogy in any culture. The last, personalistic component, refers to a teacher's self growth, highlights the role that human behaviour plays in pedagogy and without which pedagogy would merely be a conceptual discourse.

The six main influencing factors can affect, in varying ways, one or all of the four components. The political factor, often coupled with the economic, has the most powerful effect on the development or even the existence of a particular pedagogy. Political factors are particularly important when it comes to selecting a certain

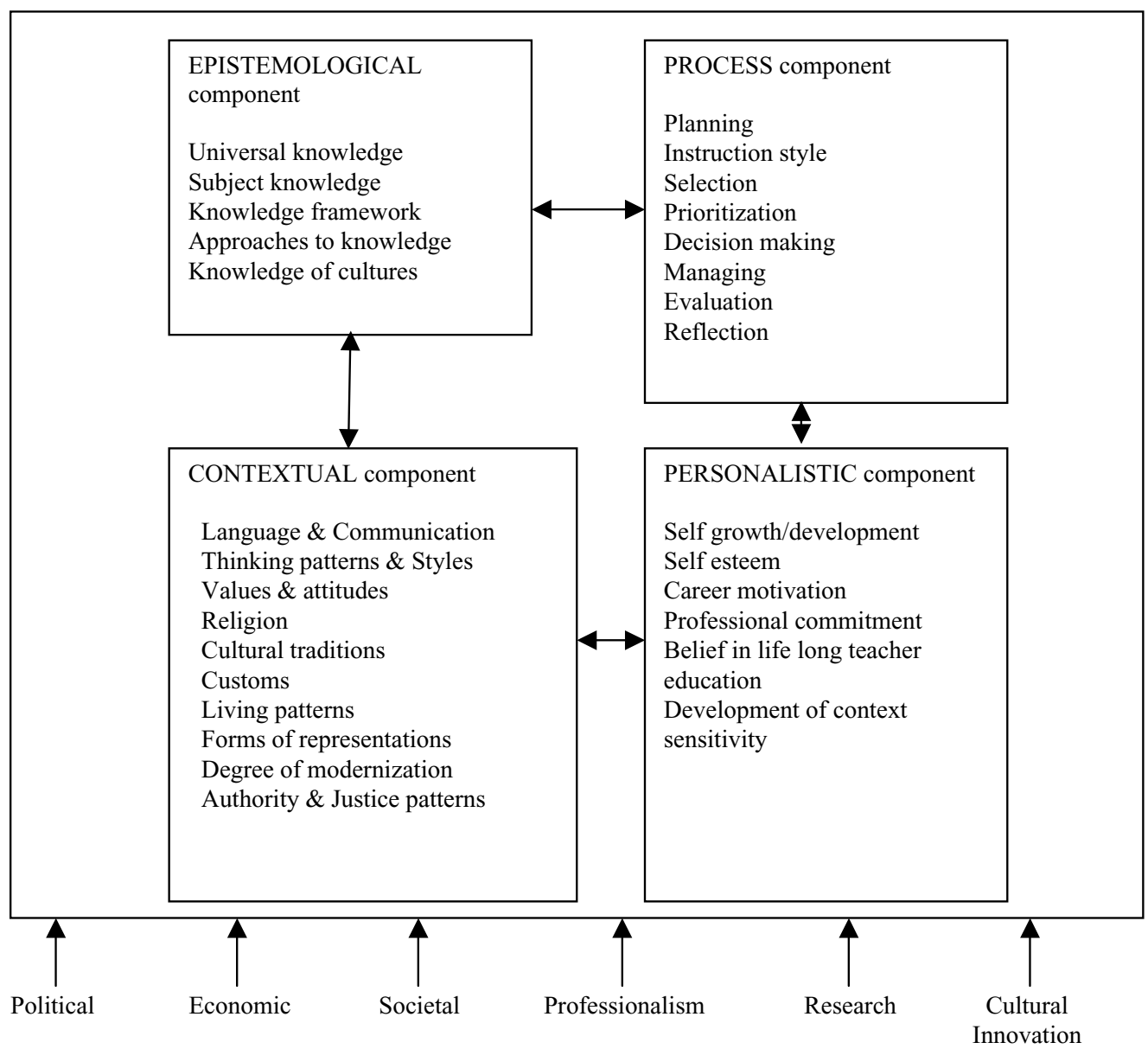

Figure 3. A pedagogical components model with main influencing factors 
educational philosophy. Economic determinants become paramount when pedagogy is perceived to be over-teacher resourced (too few or too many teachers). Societal factors relate to changing societal realities. Professionalism and the need for research and innovation are two further factors that can ensure the future quality of pedagogy, and especially affect the epistemological and personalistic components. The author claims that the final factor-the cultural factor-plays an important role, but that in many developing nations cultural heritage has suffered. Owing to modernization pressures and the urge to advance in the world competitive market, authorities in these nations have adopted external teaching and learning methods in the hope that they will help advance their economic and political control.

Thomas's definition of a culturally appropriate pedagogy is one in which each of the four pedagogy components (epistemology, process, context and personal) are so structured and integrated with one another that they actively reflect and clearly prescribe culture-specific knowledge, behaviours, attitudes and skills. The two main stages to reach such pedagogy are seen as: (1) cultural analysis, and (2) cultural selectivity. A well-designed and effectively conducted cultural analysis is an essential prerequisite. In the second stage, the outcome of analyses should provide knowledge and experiences for making each of the pedagogy's components more culturally enriching and appropriate to the cultural needs of learners and teachers.

\section{Conclusion}

This paper has discussed the notion of culturally appropriate pedagogy and various related issues. Using the example of group learning in CHC nations, we showed the dangers of applying Western-based approaches that do not take cultural complexities into account. More research is needed along the lines of Akman (1994), Nunes (1994), Teasdale and Teasdale (1994), Thomas (1997) and Walker and Dimmock (2000). Such research has proposed various models of culturally appropriate pedagogy (as shown in this paper in the examination of the work by Thomas (1997)) and demonstrated how meaningful and effective culturally rooted pedagogy can be. However, the dearth of research and essays in this area points to the urgent need to draw together relevant qualitative and quantitative cross-cultural research.

\section{Acknowledgements}

Special thanks to the Nalis family for their invaluable support.

\section{Notes}

1. Vietnamese authors' names are presented in this order: family name, middle name, first name.

2. Modern Vietnamese writing with Latinized alphabet has been in use since the beginning of the 20 th century.

3. Thomas named this pedagogy a 'culture-sensitive pedagogy'. For convenience, we switched it to the term 'culturally appropriate pedagogy', which has been used from the beginning of this paper. 


\section{Notes on contributors}

Nguyen Phuong-Mai is researcher at IVLOS Institute of Education, Utrecht University, The Netherlands. Her main research theme is intercultural education, Asian studies, instructional design and cooperative learning.

Cees Terlouw is director of ELAN Institute for Teacher Training, University of Twente, The Netherlands. His research interests concern problem solving, problem based learning and instructional design for secondary and higher education, and intercultural teaching and learning.

Albert Pilot is dean of IVLOS Institute of Education, Utrecht University, The Netherlands. His research interests concern curriculum development for secondary and higher education, intercultural teaching and learning and chemical education.

\section{References}

Achilles, C. M. (1996) Students achieve more in smaller classes, Educational Leadership, 53(5), $76-77$.

Agelasto, M. (1998) Educational disengagement: undermining academic quality at a Chinese university. Available online at: http://www.agelastos.com/disengagement/ (accessed 5 November 2004).

Akman, S. (1994) School curriculum as a forum for articulating intercultural relations with particular reference to the Peruvian Amazon, in E. Thomas (Ed.) Perspectives on schooling and culture: a symposium proceedings (London, Institute of Education, University of London), 197-218.

Ballard, B. \& Clanchy, J. (1997) Teaching international students (Deakin, ACT, IDP Education Australia).

Belenky, M. F. et al. (1997) Women's ways of knowing (New York, Basic Books).

Biggs, J. (1990) Asian students' approaches to learning: implications for teaching overseas students, paper presented at the Eighth Australian Learning and Language Conference, Queensland University of Technology.

Bradley, D. \& Bradley, M. (1984) Problems of Asian students in Australia: language, culture and education (Canberra, AGPS).

Chalmers, D. \& Volet, S. (1997) Common misconception about students from South-East Asia studying in Australia, Higher Education Research and Development, 16, 87-100

Chan, G. \& Watkins, D. (1994) Classroom environment and approaches to learning: an investigation of the actual and preferred perceptions of Hong Kong secondary school students, Instructional Science, 22, 233-246.

Chan, S. (1999) The Chinese learner - a question of style, Education and Training, 41(6/7), 294-304.

Chang, S. (2003) The tutor in multicultural environment. Available online at: http://www.dis. unimelb.edu.au/sessionals/multiculturalenv.html (accessed 24 September 2004).

Chen, M. (1995) Asian management systems: Chinese, Fapanese and Korean styles of business (London and New York, Routledge).

Cocroft, B. A. K. \& Ting-Toomey, S. (1994) Face-work in Japan and in the United States, Intercultural Fournal of Intercultural Relation, 18, 469-506.

Compact geography of the Netherlands (2001) (Utrecht, KNAG, Royal Dutch Geographical Society), 38.

Dowson, C., Bodycott, P., Walker, A \& Coniam, D. (2000) Education reform in Hong Kong: issues of consistency, connectedness and culture, Education Policy Analysis Archives, 8(24).

Earley, C. (1989) Social loafing and collectivism: a comparison of the United States and the People's Republic of China, Administrative Science Quarterly, 34(4), 565-581.

Education Law (1998) Available online at: http://www.edu.net.vn/VanBan_Luat/LuatGD_1998/ (accessed 22 May 2005). 
Flowerdew, J. \& Miller, L. (1995) On the notion of culture in L2 lectures, TESOL Quarterly, 29(2), 345-373.

Gajdusek, L. \& Gillotte, H. (1995) Teaching to the developmental needs of nonmainstream learners, New Directions for Adult and Continuing Education, 65(Spring).

Hall, E. T. (1983) The dance of life: the other dimension of time (New York, Doubleday), 43.

Hall, E. T. \& Hall, M. (1987) Hidden differences: doing business with the fapanese (Garden City, NY, Anchor Press/ Doubleday).

Harshbarger, B., Ross, T., Tafoya, S. \& Via, J. (1986) Dealing with multiple learning styles in the ESL classroom, paper presented at the Annual Meeting of Teachers of English to Speakers of Other Language, San Francisco, CA.

Hofstede, G. \& Hofstede, J. (2005) Cultures and organization-software of the minds (2nd edition) (New York, McGraw-Hill).

Jackson, P. F. (1994) 7 ways to a culturally responsive pedagogy, Education Digest, (February).

Jehn, K. \& Weldon, E. (1992) A comparative study of managerial attitudes toward conflict in the U.S and China: issues of theory and measurement, paper presented at the Academy of Management, Las Vegas, NV.

Johnson, D. W. \& Johnson, R.T. (1994) Learning together, in S. Sharan (Ed.), Handbook of cooperative learning methods (Westport, CT, Greenwood Press).

Jones, A. (1999) The Asian learner: an overview of approaches to learning (University of Melbourne, Teaching and Learning Unit Faculty of Economics and Commerce).

Kee, J. \& Wong, K. (2004) Are the learning styles of Asian international students culturally or contextually based? International Education fournal, 4(4), Educational Research Conference 2003 Special Issue.

Kennedy, P. (2002) Learning cultures and learning styles: myth-understandings about adult Hong Kong-Chinese learners, International fournal of Lifelong Education, 21(5), 430-445.

Kirkbride, P. S., Tang, S. F. Y. \& Westwood, R. I. (1991) Chinese conflict preferences and negotiating behaviour: cultural and psychological influences, Organization Studies, 12, 365-386.

Kirkpatrick, D. W. (1998) A class-ic mistake. Available online at http://www.schoolreport.com/ schoolreport/articles/AClassicMistake_6_98.htm (accessed 20 October, 2004).

Lam Phoon, S. (1986) A comparative study of the learning styles of Southeast Asian and American Caucasian college students on two Seventh-Day Adventist campuses. Dissertation Abstracts International, 48(09), 2234A.

Leung, K. (1997) Negotiation and reward allocation across cultures, in P. C. Earley \& M. Erez (Eds), New perspectives on international industrial/organization psychology (San Francisco, JosseyBass), 640-675.

Maley, A. (1983) A miracle of rare device: the teaching of English in China, in: J. M. Valdes (Ed.), Culture bound: bridging the cultural gap in language teaching (Cambridge, Cambridge University Press), 102-111.

Messier, W. P. (2003) Traditional teaching strategies versus cooperative teaching strategies: which can improve achievement scores in Chinese middle schools? Available online at: http://web.hku.hk/ $\sim$ cel2004/Proceedings/064-WilliamPMessier.doc (accessed 5August 2003).

Munro-Smith, N. (2003) A culturally aware course design, in: G. Crisp, D. Thiele, I. Scholten, S. Barker \& J. Baron (Eds), Interact, integrate, impact: Proceedings of the 20th Annual conference of the Australian Society for Computer in learning in Tertiary Education, Adelaide, 7-10 December 2003.

Neuman, Y. \& Bekerman, Z. (2000) Cultural resources and the gap between educational theory and practice, Teachers College Record, 103(3), 471-484.

Nunes, T. (1994) Cultural diversity in learning mathematics: a perspective from Brazil, in: E. Thomas (Ed.), Perspectives on schooling and culture: a symposium proceedings (London, Institute of Education, University of London), 357-370.

Oxford, R. L. \& Burry-Stock, J. A. (1995) Accessing the use of language learning strategies worldwide with ESL/EFL version of the strategy inventory for language learning, System, 23(2), 153-175. 
Park, C. C. (2002) Crosscultural differences in learning style of secondary English learners, Bilingual Research fournal. 26(2).

Phuong-Mai, N., Terlouw, C. \& Pilot, A. (2005a) Cooperative learning vs. Confucian Heritage Culture's collectivism, Asian-Europe fournal, 3(3).

Phuong-Mai, N., Terlouw, C. \& Pilot, A. (2005b) Cooperative learning vs. CHC's collectivism. The analysis in Vietnam, paper presented at ORD conference, Gent, Belgium, 30 May-1 June.

Pierson, H. (1996) Leaner culture and learner autonomy in the Hong Kong Chinese context, in: R. Pemberton, E. Li \& W. Or (Eds), Taking control: autonomy in language learning (Hong Kong, Hong Kong University Press), 49-58.

Ralston, D. A., Thang, N. V. \& Napier, N. K. (1999) A comparative study of the work values of North and South Vietnamese managers, fournal of International Business Studies, 4, 655-672.

Sadker, M., Sadker, D. \& Klein, S. (1991) The issue of gender in elementary and secondary education, in: Grant, G. (Ed.), Review of research in education (Washington, DC, American Educational Research Association), 269-334.

Salili, F. (1996) Accepting personal responsibility for learning, in: Watkin, D. and Biggs, J. (Eds), The Chinese learners: cultural, psychological and contextual influences (CERC and ACER, Hong Kong, The Central Printing Press), 86-105.

Samuelowicz, K. (1987) Learning problems of overseas students: two sides of a story, Higher Education Research and Development, 6, 121-133.

Scollon, R. \& Scollon, S. (1994) The post-Confucian confusion. Research report No. 37 (Hong Kong, City Polytechnique of Hong Kong).

Scollon, R. \& Scollon, S. (1995) Intercultural communication (Oxford, Blackwell).

Stevens, I. F. et al. (2003) Handbook of research on culturally relevant and culturally responsive educational strategies beneficial to African American students and all other students. Educational strategies extracted from the Los Angeles Unified School Districts Conference Topic Papers on Culturally Relevant Education Beneficial to African American Students and All Other Students, 31 October 2001.

Strijbos, J. W. (2000) A process-based taxonomy of group-based learning, paper presented at ORD May 2000, Leiden, The Netherlands.

Sullivan, P. N. (1996) Sociocultural influences on classroom interactional styles, TESOL fournal, 6(1), 32-34.

Suh, B. \& Price, G. E. (1993) The learning styles of gifted adolescents in Korea, in: R. M. Milgram, R. Dunn, \& G. E. Price (Eds) Teaching and counseling gifted and talented adolescents: An international learning style perspective (Westport, CT, Praeger), Chapter 11, 175-186.

Tang, C. (1996) Collaborative learning: the latent dimension in Chinese students' learning, in: Watkins, D. and Biggs, J. (Eds), The Chinese learners: cultural, psychological and contextual influences (The University of Hong Kong, Comparative Education Research Centre), 183-204.

Teasdale, R.0 \& Teasdale, J. (1994) Culture and schooling in Aboriginal Australia, in: E. Thomas (Ed.), Perspectives on schooling and culture: a symposium proceedings (London, Institute of Education, University of London), 174-196.

Thomas, E. (1997) Developing a culture-sensitive pedagogy: tackling a problem of melding 'global culture' within existing cultural context, International fournal of Educational Development, $17(1), 13-26$.

Ting-Toomey, S. (1988) Intercultural conflict styles: a face-negotiation theory, in: Y. Kim \& W. Gudykunst (Eds), Theories in intercultural communication (Newbury Park, CA, Sage), 213-235.

Tran Thi Van Anh (2002) Van de gioi trong linh vuc giao duc va phat trien nguon nhan luc [Gender problem in education and human resource development], paper presented at the Science Workshop, Social Science Research Institute [Vien xa hoi hoc], January.

Triandis, H. C. (1995) Individualism and collectivism (Boulder, CO, Westview).

Tse, D. K., Francis, J. \& Walls, J. (1994) Cultural differences in conducting intra-and intercultural negotiations: a Sino-Canadian comparison, fournal of International Business Studies, 24, 537-555. 
Tsui, A. (1996) Reticence and anxiety in second language teaching, in: K. Bailey \& D. Nunan (Eds), Voices from the language classroom (Cambridge, Cambridge University Press), 145-167.

Yong, F. L. \& Ewing, N. J. (1992) A comparative study of the learning style preferences among gifted African-American, Mexican-American, and American-born Chinese middle grade students, Roeper Review, 14(3), 120-123.

Young-Ihm, K (2002) Western influences in Korean preschools, International Education fournal, 3(3).

Wessel, R. (2003) Is there time to slow down? As the world speeds up, how cultures define the elastic nature of time may affect our environmental health. Christian Science Monitor,(Jan.), 16

Walker, A. \& Dimmock, C. (2000) One size fits all? Teacher appraisal in a Chinese culture, Fournal of Personnel Evaluation in Education, 14(2), 155-178.

Water, M. (1995) Globalization (London, Routledge).

Witty, G., Power, S. \& Halpin, D. (1998) Devolution and choice in education (Melbourne, Australian Council for Educational Research). 
